\title{
The Effects of Family-Centered Problem-Solving Education on Relapse Rate, Self Efficacy and Self Esteem Among Substance Abusers
}

\author{
Rahim Habibi, ${ }^{1}$ Alireza Nikbakht Nasrabadi, ${ }^{2}$ Maryam Shabany Hamedan,, and Amirreza \\ Saleh Moqadam ${ }^{4}$ \\ ${ }_{1}^{1}$ Deputy Dean For International Affairs, Operating Room Department, Paramedical Faculty, Qazvin University of Medical Sciences, Qazvin, IR Iran \\ 2 Deputy Dean for International Affairs, Nursing and Midwifery Faculty, Tehran University of Medical Sciences, Tehran, IR Iran \\ ${ }^{3}$ Brain and Spinal Cord Injuries Research Center, Neuroscience Institute, Tehran University of Medical Sciences, Tehran, IR Iran \\ ${ }^{4}$ Nursing Management and Mental Health Department, Nursing and Midwifery Faculty, Mashhad University of Medical Sciences, Mashhad, IR Iran \\ ${ }^{*}$ Corresponding author: Maryam Shabany Hamedan, Brain and Spinal Cord Injuries Research Center, Neuroscience Institute, Tehran University of Medical Sciences, Tehran, IR Iran. \\ Tel: +98-2177361961, E-mail: maryamshabanyi@yahoo.com
}

Received 2014 October 11; Revised 2015 February 1; Accepted 2015 February 15.

\begin{abstract}
Background:The success of drug abuse treatment and relapse prevention methods depends widely on not only pharmaceutical and nonpharmaceutical therapies but also self efficacy and self esteem promotion.

Objectives: The current study attempted to clarify the effects of Problem Solving Education (PSE) on relapse rate, self efficacy and self esteem among drug abusers.

Patients and Methods: This non-controlled clinical trial (quasi-experimental) assessed 60 opium and heroin abusers who were willing to quit and were referred to the Mehr Center of Addiction Treatment and Rehabilitation Facility. The patients were allocated to two groups of 30 (intervention and control groups). While both groups received the routine care of the clinic, the intervention group also attended eight 45-minute family-centered PSE sessions. The Coopersmith Self esteem Inventory and Quit Addiction Self efficacy Questionnaire were filled out for all subjects before and after the intervention. Drug relapse was investigated four times with two-week intervals. The two groups were compared using chi-square and Student's-t tests. Logistic regression analysis was applied to determine factors affecting drug relapse. Results: A total of 45 individuals ( 21 and 24 in the intervention and control groups, respectively) completed the study. At baseline, the two groups had no significant difference regarding their mean scores of self esteem and self efficacy $(\mathrm{P}=0.692$ and 0.329 , respectively). After the intervention, however, the mean changes of self esteem scores were $20.10 \pm 3.75$ for the intervention group and 4.50 for the control group $(\mathrm{P}<0.001)$. The mean changes of self efficacy scores in the mentioned groups were $3434.17 \pm 5.19$ and $9.03 \pm 2.04$, respectively $(\mathrm{P}<0.001)$. Drug relapse after two weeks was correlated with age $(\mathrm{OR}=1.216 ; \mathrm{P}=0.026 ; 95 \% \mathrm{CI}: 1.024-1.445)$ and implementation of the intervention $(\mathrm{OR}$ $=0.036 ; \mathrm{P}=0.003 ; 95 \% \mathrm{CI}: 0.004-0.322$ ).

Conclusions: According to our findings, supplementing drug abuse treatment with cognitive behavior therapy, particularly PSE, can reduce relapse rate and enhance self efficacy and self esteem among patients.
\end{abstract}

Keywords: Drug Users, Problem Solving, Self Efficacy, Self Esteem

\section{Background}

Substance abuse is a fundamental economic and health problem in the world, which exerts a variety of physical, psychological, and social impacts on both the person with addiction and the community (1). Use of opioids has an annual prevalence of $0.3 \%$ to $0.5 \%$ among the adult population (2).

The numerous physical complications of substance abuse include infectious diseases such as Acquired Immune Deficiency Syndrome (AIDS) and hepatitis C, liver and gastrointestinal diseases, cancers (3-5), osteoporosis (6), ischemic heart diseases (7), and even death (7, 8). On the other hand, increased stress, anxiety, depression, psychosis, loss of control and the power to decide, and decreased self efficacy are among the psychological side effects of the habit $(9,10)$.
Considering the above-mentioned complications, pharmaceutical treatments with methadone, buprenorphine and naltrexone, and non-pharmaceutical treatments have been suggested to treat this problem (11). However, research has shown a high relapse rate following withdrawal (12).

A number of physical, psychological and personality characteristics, such as self efficacy, can influence drug relapse (13). Bandura defined self efficacy as one's belief in his/her ability to plan and take appropriate steps to succeed in achieving a better situation (13). Self esteem is another crucial factor in drug abuse treatment and commitment to treatment. It provokes feelings of confidence and independence. High self esteem is associated with greater problem-solving skills and higher ability to analyze problematic situations (14-18).

Copyright (C) 2016, Zahedan University of Medical Sciences. This is an open-access article distributed under the terms of the Creative Commons Attribution-NonCommercial 4.0 International License (http://creativecommons.org/licenses/by-nc/4.0/) which permits copy and redistribute the material just in noncommercial usages, provided the original work is properly cited. 
The highest rate of opioids abuse, particularly opium and heroin, has been reported in Iran (19). Researchers have estimated the prevalence of opium abuse in the country at $1.8 \%$ to $9.0 \%$ (20-22). Despite the application of various treatment methods, drug relapse is still common in Iran (23). Therefore, designing strategies to prevent drug relapse in abusers, who have been successfully treated, seems essential. Behavioral therapy techniques, such as problem-solving education, are training methods focusing on improving skills and problem-solving attitudes (16, 17). On the other hand, family as a center for problem solving may be effective for adolescent behavioral problems in drug abusers within diverse populations, and it may be better than nonfamily alternatives (24).

Since self esteem and self efficacy can substantially decrease drug relapse, their promotion can be respected as a supportive strategy during drug abuse treatment. Also, health care providers, such as nurses, can guide and support the family in solving their problems, and provide practical care services, and induce a sense of acceptance by careful listening to concerns and suggestions of other family members (22). Furthermore, learning and application of problem solving skills is deeply felt in all nursing roles, especially in education and managerial roles, thus nurses can use the results of this study effectively (15).

\section{Objectives}

The current study sought to evaluate the effects of family-centered problem-solving education on slip (relapse) rate and levels of self efficacy and self esteem among drug abusers.

\section{Patients and Methods}

In this clinical trial, convenience sampling was applied to select the participants from all drug abusers who visited the Mehr center of addiction treatment and rehabilitation facility (Mashhad, Iran), during spring and winter 2012. Sampling lasted for six months; forty people were selected in winter and 20 people in spring. There was no gap in time and sampling depended on number of referred addicts in clinic. Furthermore, the intervention program lasted for two months. Individuals were included only if they had a non-addict, literate family member who agreed to participate in the study and problem-solving sessions, were Iranian citizens, had lived in Mashhad for at least five years, aged between 16 and 40 years old, and could read and write. Addiction was confirmed by the facility's physician based on patient records. Other inclusion criteria were heroin or opium abuse, history of addiction less than ten years, not having experienced more than two relapses, absence of drug dependence, and not having attended a formal training course on addiction. Finally, the participants (either the patients or their family members) could not be health personnel.

During the course of the study, subjects who developed psychological disorders, chronic and progressive diseases such as cancer and diabetes, and infectious diseases like AIDS and hepatitis, according to the facility's specialists, were excluded. The intervention group members who failed to participate in training classes or more than one problem-solving education session were also excluded. Besides, unwillingness of the participants and/ or their family members to continue the treatment program led to their exclusion.

Based on similar clinical trials, the sample size was calculated using the difference in means formula and considering the maximum number of subjects and self efficacy as the dependent variable.

$$
n=\frac{\left[Z_{1-\frac{\alpha}{2}}+Z_{1-\beta}\right]^{2}\left(S_{1}^{2}+S_{2}^{2}\right)}{\left(X_{1}-X_{2}\right)^{2}}
$$

With Confidence Interval (CI) and test power equal to $95 \%(\alpha=5 \%)$ and $80 \%(\beta=20 \%)$, respectively, the sample size was determined as 30 . The selected subjects were then allocated to either intervention or control group using coin flips.

At the beginning of the study, the participants were asked to provide written informed consent and introduced an eligible family member with whom they felt more comfortable. A questionnaire containing demographic characteristics, the Coopersmith Self Esteem Inventory (CSEI), and Quit Addiction Self Efficacy Questionnaire (QASEQ) were filled out for all subjects at baseline. The latter is a 16-item questionnaire designed by Bramson to assess self efficacy in drug dependent patients. It measures problem solving, decision-making, self-expression, and relationship skills using questions scored based on a seven-point Likert scale (with scores one to seven for definitely no, probably no, perhaps no, no idea, perhaps yes, probably yes, definitely yes, respectively) resulting in a total score of 16 to 112. The validity of the QASEQ was confirmed by Martin (1995) and Bramson (1999) Face and content validity of the Farsi version of the QASEQ was also evaluated by Habibi et al. who reported the correlation between QASEQ and the General Self Efficacy Questionnaire (a validated questionnaire in Iran) as $\mathrm{r}=0.6(\mathrm{P}<$ $0.001)(25)$. The reliability of the tool was also approved by a Cronbach's alpha value of 0.90 (25).

The CSEI was developed and utilized by Coopersmith to gauge general self esteem (26-28). It consists of 35 items on a four-point Likert scale (1: strongly agree; 2 : agree; 3 : disagree; 4 : strongly disagree), which yield a total score of 35-140. We categorized self esteem as low, moderate and high (scores: 35-70, 71-105, and 106-140, respectively) in the present study. Moreover, in order to examine the reliability of the questionnaire, it was distributed among 20 drug addicts and completed again by the same population after ten days (test-retest method). Finally, a reliability coefficient of $\mathrm{r}=0.85$ suggested the CSEI to be acceptably reliable. 
Habibi Ret al.

The intervention was initiated after the questionnaires had been completed. Both groups received routine care, including weekly meetings with the physician and a minimum of biweekly psychological counseling and social work services, at the facility for two months. The intervention group and their family members also participated in a problem-solving education course, which comprised of eight 45-minute weekly sessions and covered physical, psychological and social-family problems. The education started with sessions to pose the question and continued with data collection, hypotheses formulation and testing, conclusion, and final evaluation, which are the five steps of problem solvingeducation. In order for the families to reach solutions faster, they were presented with previously prepared handouts. Eight sessions were held and in the first session, the researcher explained the study objectives, and became familiar with families and their points of view. Next, families were divided to three groups of ten for participation in future group discussions.

In the second session, the researcher defined the terms addiction and addict, variety of addictions, causes and roots, common treatments, and problem solving training method in simple words for the study subjects in each group. In this session, problems were identified and classified in three areas of physical, mental, and socialfamily. The effected family member had to collect information about solutions to the problems, by studying educational notes and using other sources such as radio, TV, the internet, books, etc.

In the third session, study subjects were encouraged to suggest the best and most suitable solutions for the problems of the patients in the physical area, thus they listed the problems faced by their patient.

In the fourth session, study subjects were asked to describe the best and most suitable solutions for their patients' problems. By the end of the fourth session, the researcher pursued progress of the effected family members in solving physical problems of the patients.

In the fifth session, study subjects were asked to describe the best and most suitable solutions they could think of for their patients' psychological problems. At the end of the fifth session, the researcher followed up the status of solutions of patient's psychological problems by the effected family member.

In the sixth session, in addition to following up progress of solving patient's social-family problems by the effected family member, the researcher also pursued implemented solutions and all the steps taken by this stage, answered the questions raised by the families with assistance of the psychiatrist, social worker and clinic's psychologist.

In the seventh session, a meeting was held with participation of drug-dependent patients and patients could be familiarized with problem solving techniques and how they should cooperate with their families.

In the eighth and final session, the researcher with co- operation of families, social worker and clinic's psychologist and using group discussions, followed up patients' comments from previous sessions, and answered their questions.

Generally, during each session, patients and their family members brainstormed patient problems and various solutions were proposed by patients, families, the researcher, and the facility's psychologist and social worker. In the meantime, the researcher responded to the participants' questions via direct contact during training sessions and regular phone calls throughout the course of the study.

Once problem-solving education was complete, both groups filled out the QASEQ and CSEI for a second time. In both groups, drug relapse (slip) was assessed using a morphine test device (ACON, USA), every two weeks, and the results were recorded. The test is commonly implemented as a valid tool in addiction treatment clinics in Iran. The reliability and validity of this particular kit have been previously confirmed, using the test-retest method ( $r=0.91$ ) by Habibi et al. (25).

The collected data was analyzed with the SPSS software for Windows 20.0 (SPSS Inc., Chicago, IL, USA). Paired ttests were applied to determine intergroup differences between the scores before and after the intervention. Intergroup comparisons between the mean changes of the scores and the frequency of drug relapse were made using Student's t-test and both chi-square and Fisher's exact tests, respectively. Logistic regression analysis was performed to identify possible factors affecting relapse, e.g. demographic characteristics (age, gender, marital status, income and education level), the relationship between the patient and his/her family member, type of abused drug, duration of addiction, implementation of the intervention, and mean changes of self efficacy and self esteem scores. Analysis of Covariance (ANCOVA) was carried out to determine factors affecting self esteem and self efficacy scores after the intervention. Also, repeated measure ANOVA analysis was used to evaluate scores within and between groups. Again, the mentioned demographic characteristics, the relationship between the patient and his/her family member, type of abused drug, duration of addiction, implementation of the intervention, and baseline scores of self esteem and self efficacy were included.

\subsection{Ethics Committee Approval and Monitoring}

This research was completed as part of a graduate student project, code 89392 and under the Research Council of Mashhad University of Medical Sciences and the University Ethics Committee approved the study) number 3142/511 dated Sunday, January 16th, 2011) (10.26.1389 in Shamsi).

\section{Results}

The present study evaluated 60 individuals in two groups of 30 (i.e. intervention and control). Twenty-one 
Habibi Ret al.

patients from the intervention group and 24 patients from the control group completed the study and underwent all relapse tests. The mean age of patients was 34.27 \pm 3.30 years (range: $21-40$ years). The intervention and control groups were matched in terms of mean age. Table 1 shows baseline characteristic information of patients included in this study.

Table 2 compares the scores of the two groups in terms of self efficacy and self esteem scores before and after the intervention.
According to Table 2, the mean scores of self efficacy and self esteem of both groups increased significantly after the intervention. Also, repeated measure Analysis of Variance (ANOVA) to evaluate within and between groups was done. It showed significant differences within groups (during the time) and between groups for both self esteem and self efficacy.

The mean changes of self efficacy and self esteem scores along with the frequency of relapse are presented in Table 3.

\begin{tabular}{|c|c|c|c|}
\hline Variable & Control Group $(n=30)^{a}$ & Intervention Group $(n=30)^{a}$ & P Value \\
\hline Age, $y$ & $34.33 \pm 5.88$ & $34.20 \pm 5.60$ & 0.929 \\
\hline \multicolumn{4}{|l|}{ Family member } \\
\hline Age & $31.43 \pm 5.59$ & $31.47 \pm 6.30$ & 0.983 \\
\hline Relationship (spouse) & $26(86.7)$ & $22(73.3)$ & 0.197 \\
\hline Gender & & & 1.000 \\
\hline Male & $28(93.3)$ & $28(93.3)$ & \\
\hline Female & $2(6.7)$ & $2(6.7)$ & \\
\hline Reason for quitting & & & 0.936 \\
\hline Patient's will & $11(36.7)$ & $9(30.0)$ & \\
\hline Family issues & $7(23.3)$ & $7(23.3)$ & \\
\hline Cost of drugs & $5(16.7)$ & $8(26.7)$ & \\
\hline Work issues & $3(10.0)$ & $3(10.0)$ & \\
\hline Physical and mental issues & $4(13.3)$ & $3(10.0)$ & \\
\hline Marital status (married) & $26(86.7)$ & $24(80.0)$ & 0.488 \\
\hline $\begin{array}{l}\text { Education level (high school and } \\
\text { more) }\end{array}$ & $8(26.7)$ & $7(23.3)$ & 0.766 \\
\hline Income (adequate) & $11(36.7)$ & $15(50.0)$ & 0.297 \\
\hline Employed & $23(76.7)$ & $21(70.0)$ & 0.960 \\
\hline Owning a house & $16(53.3)$ & $12(40)$ & 0.301 \\
\hline Type of drug abuse & & & 0.569 \\
\hline Injection & $2(6.7)$ & $2(6.7)$ & \\
\hline Inhalation & $16(53.3)$ & $12(40.0)$ & \\
\hline Oral & $12(40.0)$ & $16(53.3)$ & \\
\hline History of drug abuse (years) & $5.13 \pm 2.66$ & $5.00 \pm 2.56$ & 0.844 \\
\hline Smoking more than 10 cigarettes a day & $16(53.4)$ & $17(56.6)$ & 0.925 \\
\hline Having an addict family member & $10(33.3)$ & $9(30.0)$ & 0.781 \\
\hline Type of drug & & & 0.438 \\
\hline Opium & $17(56.7)$ & $14(46.7)$ & \\
\hline Heroin & $13(43.3)$ & $16(53.3)$ & \\
\hline Monthly cost of drugs (10000 Rials) & $20.65 \pm 13.65$ & $19.42 \pm 12.30$ & 0.714 \\
\hline Drug usage (g/month) & $7.77 \pm 3.78$ & $8.00 \pm 4.27$ & 0.823 \\
\hline
\end{tabular}

\footnotetext{
${ }^{\mathrm{a}}$ Data are presented as mean \pm SD and No. (\%).
} 
Habibi Retal.

Table 2. Mean Scores of Self Efficacy and Self Esteem Before, After and During Follow up

\begin{tabular}{lccccc}
\hline & Before & After & Follow Up & $\begin{array}{c}\text { P Value (Test Within } \\
\text { Subjects) }\end{array}$ & $\begin{array}{c}\text { P Value (Test Between } \\
\text { Subjects) }\end{array}$ \\
\hline Self esteem & & & & & 0.041 \\
\hline Intervention & $88.57 \pm 21.20$ & $108.67 \pm 19.49$ & $117.53 \pm 9.08$ & $<0.001$ & $<0.001$ \\
\hline $\begin{array}{c}\text { Control } \\
\text { Self efficacy }\end{array}$ & $90.80 \pm 22.18$ & $95.30 \pm 22.43$ & $95.63 \pm 22.75$ & $<0.001$ & \\
\hline $\begin{array}{l}\text { Intervention } \\
\text { Control }\end{array}$ & $61.13 \pm 8.53$ & $95.30 \pm 9.08$ & $104.03 \pm 7.06$ & & $<0.001$ \\
\hline
\end{tabular}

Table 3. Mean Changes of Self Efficacy and Self Esteem Scores and Frequency of Relapse at Specific Intervals for the Intervention and Control Groups

\begin{tabular}{lccc}
\hline & Control Group & Intervention Group & P Value \\
\hline Self esteem score & $95.30 \pm 22.43$ & $108.67 \pm 19.49$ & 0.017 \\
Changes in self esteem score & 4.50 & $20.10 \pm 3.75$ & $<0.001$ \\
Self efficacy score & $72.37 \pm 9.35$ & $95.30 \pm 9.08$ & $<0.001$ \\
Changes in self efficacy score & $9.03 \pm 2.04$ & $34.17 \pm 5.19$ & $<0.001$ \\
\hline Drug relapse, No(\%) & & & 0.117 \\
\hline Second week & $9(30.0)$ & $4(13.3)$ & 0.053 \\
\hline Fourth week & $9(30.0)$ & $3(10)$ & 0.002 \\
\hline Sixth week & $12(40.0)$ & $2(6.7)$ & $<0.001$ \\
\hline Eighth week & $13(43.3)$ & $1(3.3)$ & \\
\hline
\end{tabular}

The mean changes of self efficacy and self esteem scores were significantly higher in the intervention group than in the control group. Moreover, compared to the intervention group, the control group had significantly greater frequency of relapse two, six and eight weeks after baseline. On the whole, the frequency of relapse reduced in the intervention group and increased in the control group with passing time.

The ANCOVA results revealed that implementation of the intervention, baseline self esteem score, monthly income, and type of abused drug had significant relationships with increased self esteem score at the end of the study. On the other hand, implementation of the intervention and baseline self efficacy scores had significant effects on the final self efficacy scores.

Logistic regression analysis suggested the relapse on the eighth week to be significantly correlated with age (odds ratio:1.216; 95\% CI:1.024-1.445; $\mathrm{P}=0.026$ ) and implementation of the intervention (odds ratio: 0.036; $95 \% \mathrm{CI}$ : 0.004-0.322; $\mathrm{P}=0.003$ ).

\section{Discussion}

The present study indicated that problem-solving education in presence of a family member (as the supporter) significantly promotes self efficacy and self esteem among drug abusers throughout the process of quitting. Furthermore, the frequency of relapse was significantly higher in the control group than in the intervention group. Hogue et al. in their study found that family ther- apy may be effective for adolescent behavior problems in drug abusers within diverse populations, and it may be better than nonfamily alternatives (24).

Opioids abuse treatment programs may be categorized as pharmaceutical treatments with methadone, buprenorphine and naltrexone, and non-pharmaceutical treatments including counseling and behavioral therapies (11).

Despite the presence of comprehensive plans, drug relapse has been reported in various studies. Dunn et al. in a review of 28 studies on relapse rate following addiction treatment with buprenorphine, found that the median frequency of individuals who stayed serious in quitting addiction during the follow-up period was $23 \%$. Interestingly, in five studies, only $30 \%$ of the participants had continued abstinence from drugs until the last day of treatment (29).

Drug relapse might occur as a result of several factors including the stressful nature of withdrawal, properties of prescribed medicines and external factors such as stressors (30). Inadequate treatment due to lack of medical personnel and facilities, counseling, occupational therapy, and post-treatment education in addiction treatment centers can also be responsible for drug relapse (31). On the other hand, different treatment modalities, especially with methadone, have to be accompanied by behavioral treatment. Research has in fact shown the absence of the latter to increase the frequency of relapse (32). 
The frequency of drug relapse has also been evaluated in Iran. Shirinbayan et al. examined the frequency of sobriety for seven methadone treatment centers in four cities of Iran and concluded that $17.7 \%$ had resumed abuse simultaneous with treatment. Long distance to the clinic, absence of family and social support, and lack of determination were introduced as factors affecting relapse rate (33).

Marlatt and Donovan proposed Cognitive-Behavioral Treatment (CBT) as an efficient way to reduce relapse rate (34). Problem-solving education, performed in the current research, is a CBT method where individuals become actively involved in discussing and solving their own problems as well as the others (35). Our findings highlighted the significant difference in relapse rate between the intervention and control groups. The intervention group compared with the control group had higher scores in self efficacy and self esteem. Nevertheless, logistic regression analysis asserted the implementation of intervention and younger age as the only preventive factors of relapse.

A remarkable finding of the present research was the increased mean self efficacy and self esteem scores as a consequence of the intervention. As self efficacy is a major component of success, and reflects one's belief in one's ability to perform tasks (36), its enhancement may reduce drug relapse. Miller et al. reviewed ten studies on self efficacy promotion and behavior modification among cigarette smokers and alcohol and drug abusers. They observed increased self efficacy in only six studies out of which two had reported behavioral changes regarding addiction. While none of the mentioned studies had assessed the direct effects of increased self efficacy on addiction management and treatment, Miller et al. hypothesized that self efficacy might cause behavioral improvements in addicts (37).

Another noteworthy result of the current study was the gradual reduction in frequency of relapse. The substantial intergroup difference in relapse rate (3.3\% in the intervention group vs. $43.3 \%$ in the control group) despite similar baseline characteristics, pharmaceutical treatment and counseling, contends the efficacy of CBT, i.e. problem-solving education in the presence of a supportive family member. The benefits of CBT have also been demonstrated in previous studies. Pashaei et al. analyzed the effectiveness of methadone treatment alone and in combination with CBT and suggested the second to lead to considerably lower relapse rates (38).

According to the result, it is suggested for policy makers to conduct education courses about family and addiction for physicians and health workers of addiction treatment centers. It is suggested for physicians and health workers to take part in these courses.

Findings of the present study highlighted the significant effects of problem-solving education on improving self efficacy and self esteem scores and reducing relapse during the course of treatment. Supplementing addiction treatment modalities with CBT is thus recommended. Besides, further studies to compare various CBT methods, including problem-solving education, are indispensable for designing more successful interventions in the future.

\section{Acknowledgments}

The researchers are grateful to Dr. Latifnejad (Research Deputy of Mashhad Nursing and Midwifery School), Dr. Afsari (psychiatrist, chief of Mehr Addiction Treatment and Rehabilitation Facility), Ms. Monfared (social work expert), Ms. Hakimi (psychologist) and all other personnel and patients of Mehr Addiction Treatment and Rehabilitation Facility.

\section{Footnotes}

Authors' Contribution:Study concept and design: Rahim Habibi; acquisition of data: Rahim Habibi; analysis and interpretation of data: Rahim Habibi and Maryam Shabany; drafting of the manuscript: Maryam Shabany; critical revision of the manuscript for important intellectual content: Maryam Shabany; statistical analysis: Rahim Habibi and Professor Nikbakht; administrative, technical, and material support: Rahim Habibi; study supervision: Amirreza saleh moqadam.

Funding and Support:Mr. Habibi reported that he had received a research grant from The Mashhad University of Medical Science and he refunded the money to the university.

\section{References}

1. Chen CY, Lin KM. Health consequences of illegal drug use. Curr Opin Psychiatry. 2009;22(3):287-92. [PubMed:19378381]

2. UNODC. World Drug Report 2012. Vienna: United Nations publication; 2012.

3. Aliasgari MA, Kaviani A, Gachkar L, Hosseini-Nassab SR. Is bladder cancer more common among opium addicts? Urol J 2004;1(4):253-5. [PubMed:17914701]

4. Ghadirian P, Stein GF, Gorodetzky C, Roberfroid MB, Mahon GA Bartsch $\mathrm{H}$, et al. Oesophageal cancer studies in the Caspian littoral of Iran: some residual results, including opium use as a risk factor. Int J Cancer. 1985;35(5):593-7. [PubMed: 3997280]

5. Mousavi MR, Damghani MA, Haghdoust AA, Khamesipour A. Opium and risk of laryngeal cancer. Laryngoscope. 2003;113(11):193943. [PubMed:14603052]

6. Gozashti MH, Shahesmaeili A, Amini Zadeh N. Is opium addiction a risk factor for bone loss? Iran Red Crescent Med J. 2011;13(7):4648. [PubMed: 22737513]

7. Khosoosi Niaki MR, Hamid M, Farshidi F, Mohammadpour M Salehi Omran MT. Evaluation of the role of opium addiction in acute myocardial infarction as a risk factor. Caspian J Intern Med. 2013;4(1):585-9. [PubMed: 24009941]

8. Khademi H, Malekzadeh R, Pourshams A, Jafari E, Salahi R, Semnani S, et al. Opium use and mortality in Golestan Cohort Study: prospective cohort study of 50,000 adults in Iran. BMJ. 2012;344:e2502. doi:10.1136/bmj.e2502. [PubMed: 22511302]

9. Preston KL, Epstein DH. Stress in the daily lives of cocaine and heroin users: relationship to mood, craving, relapse triggers, and cocaine use. Psychopharmacology (Berl). 2011;218(1):29-37. doi 10.1007/s00213-011-2183-x. [PubMed: 21336579]

10. Teesson M, Havard A, Fairbairn S, Ross J, Lynskey M, Darke S. Depression among entrants to treatment for heroin depen- 
Habibi Retal.

dence in the Australian Treatment Outcome Study (ATOS): prevalence, correlates and treatment seeking. Drug Alcohol Depend. 2005;78(3):309-15. doi: 10.1016/j.drugalcdep.2004.12.001. [PubMed: 15893162]

11. American Psychiatric Association Practice G. Practice guideline for the treatment of patients with borderline personality disorder. American Psychiatric Association. Am JPsychiatry. 2001;158(10 Suppl):1-52. [PubMed:11665545]

12. Adi Y, Juarez-Garcia A, Wang D, Jowett S, Frew E, Day E, et al. Oral naltrexone as a treatment for relapse prevention in formerly opioid-dependent drug users: a systematic review and economic evaluation. Health Technol Assess. 2007;11(6):iii-v. [PubMed: 17280624]

13. Bandura A. Self efficacy: toward a unifying theory of behavioral change. Psychol Rev. 1977;84(2):191-215. [PubMed: 847061]

14. Baumeister RF, Smart L, Boden JM. Relation of threatened egotism to violence and aggression: the dark side of high self esteem. Psychol Rev. 1996;103(1):5-33. [PubMed: 8650299]

15. Bushman BJ, Baumeister RF. Threatened egotism, narcissism, self esteem, and direct and displaced aggression: does self-love or self-hate lead to violence? J Pers Soc Psychol. 1998;75(1):219-29. [PubMed: 9686460]

16. Bushman BJ, Baumeister RF, Thomaes S, Ryu E, Begeer S, West SG. Looking again, and harder, for a link between low self esteem and aggression. J Pers. 2009;77(2):427-46. doi: 10.1111/j.14676494.2008.00553.x. [PubMed:19192074]

17. Maslow AH. Motivation and personality. Harper \& Row; 1981.

18. Hassanian-Moghaddam H, Afzali S, Pooya A. Withdrawal syndrome caused by naltrexone in opioid abusers. Hum Exp Toxicol. 2014;33(6):561-7. doi: 10.1177/0960327112450901. [PubMed: 23690227]

19. Masoumi M, Shahesmaeili A, Mirzazadeh A, Tavakoli M, Ali AZ. Opium addiction and severity of coronary artery disease: a casecontrol study.J Res Med Sci. 2010;15(1):27-32. [PubMed: 21526055]

20. Ahmadi J, Naghshvarian M, Afshari R. Opioids use in male population referred for mandatory urine opioid screen before marriage in shiraz-iran. Iran J Psychiatry Behav Sci. 2011;5(2):126-30. [PubMed: 24644457]

21. UNODC. World Drug Report 2009. Vienna: United Nations Publications; 2009.

22. Mokri A. Brief overview of the status of drug abuse in Iran. Arch Iranian Med. 2002;5(3):184-90.

23. Najafi K, Amir Alavi C, Zarrabi H, Mohammadzadeh A, Khodaei E Salajegeh A. Survey the Prevalence of Recurrence in Uktra Rapid Opiate Detoxification in Opiate and Heroin Dependents.J Guilan Univ Med Sci. 2008;17(67):55-64.

24. Hogue A, Dauber S, Henderson CE, Bobek M, Johnson C, Lichvar E, et al. Randomized Trial of Family Therapy Versus Nonfamily Treatment for Adolescent Behavior Problems in Usual Care. J Clin Child Adolesc Psychol. 2015;44(6):954-69. doi:
10.1080/15374416.2014.963857. [PubMed: 25496283]

25. Habibi R, Karshky H, Dashtgard A, Heidary A, Talaei A. [Validity The Reliability of The Bramson's Quit Addiction Self Efficacy Questionnaire]. Hakim. 2012;15(1):53-9.

26. Chiu LH. The Reliability and Validity of the Coopersmith Self esteem Inventory-Form B. Educational and Psychological Measurement. 1985;45(4):945-9. doi: 10.1177/0013164485454027.

27. Johnson BW, Redfield DL, Miller RL, Simpson RE. The Coopersmith Self esteem Inventory: A Construct Validation Study. Educational and Psychological Measurement. 1983;43(3):907-13. doi: 10.1177/001316448304300332.

28. Myhill J, Lorr M. The coopersmith self esteem inventory: Analysis andpartialvalidation of amodifiedadultform.JournalofClinicalPsychology.1978;34(1):72-6. doi:10.1002/1097-4679(197801)34:1<72::AIDJCLP2270340115>3.0.CO;2-T. [PubMed: 641187]

29. Dunn KE, Sigmon SC, Strain EC, Heil SH, Higgins ST. The association between outpatient buprenorphine detoxification duration and clinical treatment outcomes: a review. Drug Alcohol Depend. 2011;119(1-2):1-9. doi: 10.1016/j.drugalcdep.2011.05.033. [PubMed: 21741781]

30. Smith RJ, Aston-Jones G. Noradrenergic transmission in the extended amygdala: role in increased drug-seeking and relapse during protracted drug abstinence. Brain Struct Funct. 2008;213(12):43-61. doi:10.1007/s00429-008-0191-3. [PubMed:18651175]

31. U.S. Department of State. International Narcotics Control Strategy Report; 2011.

32. Kresina TF, Bruce RD, Pirard S, Mulvey K, Huesca RS. International Expansion of the Use of Pharmacotherapies for the Treatment of Opioid Dependence. Clin Exp Pharmacol. 2012:S5-01.

33. Shirinbayan P, Rafiey H, Vejdani Roshan A, Narenjiha H, Farhoudian A. Alcohol and Alcoholism. 2010;5(suppl 1):3231-6.

34. Marlatt GA, Donovan DM. Relapse Prevention, Second Edition: Maintenance Strategies in the Treatment of Addictive Behaviors. Guilford Publications; 2005.

35. Feinberg E, Augustyn M, Fitzgerald E, Sandler J, Ferreira-Cesar Suarez Z, Chen N, et al. Improving maternal mental health after a child's diagnosis of autism spectrum disorder: results from a randomized clinical trial. JAMA Pediatr. 2014;168(1):40-6. doi: 10.1001/jamapediatrics.2013.3445. [PubMed: 24217336]

36. Lopez SJ, Snyder CR. The Oxford Handbook of Positive Psychology. OUP USA; 2011.

37. Miller KJ, McCrady BS, Abrams DB, Labouvie EW. Taking an individualized approach to the assessment of self efficacy and the prediction of alcoholic relapse. Journal of Psychopathology and Behavioral Assessment. 1994;16(2):111-20. doi: $10.1007 / B F 02232722$.

38. Pashaei T, Shojaeizadeh D, Rahimi Foroushani A, Ghazitabatabae M, Moeeni M, Rajati F, et al. Effectiveness of Relapse Prevention Cognitive-Behavioral Model in Opioid-Dependent Patients Participating in the Methadone Maintenance Treatment in Iran.Iran J Public Health. 2013;42(8):896-902. [PubMed:26056645] 